UDC 528.721.22

\title{
ACCURACY ANALYSIS OF MEASURING CLOSE-RANGE IMAGE POINTS USING MANUAL AND STEREO MODES
}

\author{
Jūratė Sužiedelytè-Visockienè \\ Department of Geodesy and Cadastre, Faculty of Environmental Engineering, \\ Vilnius Gediminas Technical University, Sauletekio al. 11, LT-10223 Vilnius, Lithuania \\ E-mail: jurate.visockiene@vgtu.lt
}

Received 02 February 2013; accepted 26 February 2013

\begin{abstract}
The performed investigations are aimed at estimating the accuracy of image processing using different image point measurements. For this purpose, digital close-range images were processed applying photogrammetric software PhotoMod. The measurements have been made employing two methods: stereo and manual mode. Two or more overlapping images are matched when control and tie points are estimated.

The images of two objects have been taken for experimental investigation. Control points and tie points were measured switching either to stereo or manual mode applying the required software. The control points of the first object are distributed on the surface of a smooth facade and on the surface of different (a few) levels. The process of image matching includes the calculation of the correlation coefficient, vertical parallax residuals and the root mean square of the object. Following image transformation (adjustment processes) to the created 3D model, the accuracy of the measured points is determined. All these values show the precision of close-range photogrammetric processes. Such accuracy satisfies requirements for creating a proper digital terrain model and orthophoto generation.
\end{abstract}

Keywords: close-range photogrammetry, correlation coefficient, manual mode, stereo mode.

Reference to this paper should be made as follows: Sužiedelyte்-Visockienė, J. 2013. Accuracy analysis of measuring close-range image points using manual and stereo modes, Geodesy and Cartography 39(1): 18-22.

\section{Introduction}

The photogrammetric method of object measurement processes consists of taking images of an object employing a professional calibrated photo-camera and processing these images applying appropriate software. To obtain highly accurate and reliable results, it is necessary to control the capture of photo images and processing accuracy. The processes of photogrammetric images cover relative and absolute orientation, bundle adjustment, stereo-digitalisation, digital terrain model generation and orthophoto creation. A geometric model of the object is made of relative orientation that embraces the interior orientation of the image and matching the image. The point measurements of the images can be divided into two methods: stereo mode and manual mode. When the geometric model of the object is produced using stereo mode, an operator can measure the points (control (CP) and Tie points) with special glasses. The operator can observe a three-dimensional object through the image view on the computer screen and carry out measurements in both photo images at the same time. During manual measurements, the points are estimated separately in each of the images and then processed adopting a correlation approach or applying to least-square adjustment techniques. The value of correlation coefficients shows how accuracy at that particular point is measured. The quality of the obtained results is estimated by vertical parallax residuals in the measured points and root mean square (RMS) geometric models.

The goal of the carried out experiments is to respond to the below introduced questions:

1. What available and acceptable maximum value of the correlation coefficient will be used for measuring the points employing manual methods in overlapping images?

2. What errors of vertical parallax residuals and RMS will be used for measuring manual or stereo modes in overlapping images?

\section{Calculation of the correlation coefficient}

The correlation coefficient is used for a close range photogrammetric application of image point measurements. 
Applications include a comparison of two overlapping images for the purposes of image registration, $\mathrm{CP}$ or Tie point recognition and measurement. The correlation coefficient $(q)$ is calculated according to the formula (Potůčková 2004; Mileškaitè 2011)

$$
q=\frac{q_{L R}}{q_{L} \times q_{R}},
$$

where $q_{L R}$ - the covariance of left and right image patches; $q_{L}$ - the standard deviation of image patch $\mathrm{L}$ (left image); $q_{R}$ - the standard deviation of image patch $\mathrm{R}$ (right image).

The correlation coefficient $(q)$ has value $-1 \leq q \geq 1$. $q=1$ if two overlapping images are absolutely identical, $q=0$ if they are completely uncorrelated (stereo point measurement) and $q=-1$ if they are completely anti-correlated when the left image is a negative right image.

For digital colour image processing, an equation for the correlation coefficient can be modified using a mean value of three channels as a single similarity measure (Potůčková 2004; Mileškaitė 2011):

$$
q=\frac{q^{\text {red }}+q^{\text {green }}+q^{\text {blue }}}{3} .
$$

Correlation coefficients are calculated considering two overlapping images during the relative orientation of photogrammetric processes in the following way (Hanke, Grussenmeyer Corfu 2002):

1. Measuring Tie points of stereo pairs (models) in overlapping areas and triplet zone (in case we have more than two images) images.

2. Input value of coordinates and measuring $\mathrm{CP}$ in the overlapping image.

3. Accuracy control using the correlation coefficient that is calculated applying the manual point measurement method in overlapping images. When the points are measured by stereo mode, the correlation coefficient is not calculated $(q=0)$.

4. Accuracy control using vertical parallax residual. After measuring the points on the images, the relative orientation parameters of the images are calculated. They are the maximum error of vertical parallax residuals $\left(E_{\max }\right)$ and the root mean squared error (RMS) (Kiseleva 2002):

$$
\begin{aligned}
& E_{\text {max }}=2 \times E_{\text {mean }}, \\
& R M S=\sqrt{2} \times E_{\text {mean }} .
\end{aligned}
$$

where $E_{\text {mean }}-$ is a mean error of measurement points on overlapping images. $E_{\text {mean }}$ error should not be greater than a half of pixel size in a camera matrix.

After measuring Tie and CP in stereo pairs (models), they should be transferred to the geodetic coordinate system. Relative orientation accuracy can be checked comparing the discrepancies of point measurements in adjacent models (triplets). Triplet errors $E_{X}, E_{Y}, E_{Z}$ in their coordinates $\mathrm{X}, \mathrm{Y}$ and $\mathrm{Z}$ were calculated for two adjacent models. The mean errors of measurement points in the XY plane and $\mathrm{Z}$ coordinates are calculated by the following formulas (Kiseleva 2002):

$$
\begin{aligned}
& E_{x y(\text { mean })}=\sqrt{2} \times 0.5 \times p x l, \\
& E_{z(\text { mean })}=\frac{c}{b_{x}} E_{x y(\text { mean }),}
\end{aligned}
$$

where $p x l$ - pixel size in a camera matrix; $c$ - the focal length of the camera; $b_{x}$ - photographic base in the image scale.

\section{Experimental works}

To evaluate the possibilities of point matching methods creating the $3 \mathrm{D}$ model, the fragment of two heritage objects was chosen. The first one is a church built in 1881 in the settlement of Raudenai, Šiauliai municipality, Lithuania. The second object is a farm building in Arnioniai manor, Moletai municipality, Lithuania. Both objects were reconstructed last year. During reconstruction, it was necessary to have photogrammetric fixation of the object facade.

Thus, colour digital images of two objects were taken by the professional digital photo-camera Canon EOS 1D Mark III (Figs. 1 and 2) that was calibrated (optical distortions were determined and evaluated) using Tcc software at the Institute of Photogrammetry in the University of Bohn (Germany) in 2008 and 2012 (Sužiedelytė-Visockienė, Bručas 2009a, b; SužiedelytèVisockienè 2012). The focal length of the camera is $50.76 \mathrm{~mm}$ and pixel size in a camera matrix $p x l=6.4 \mu \mathrm{m}$.

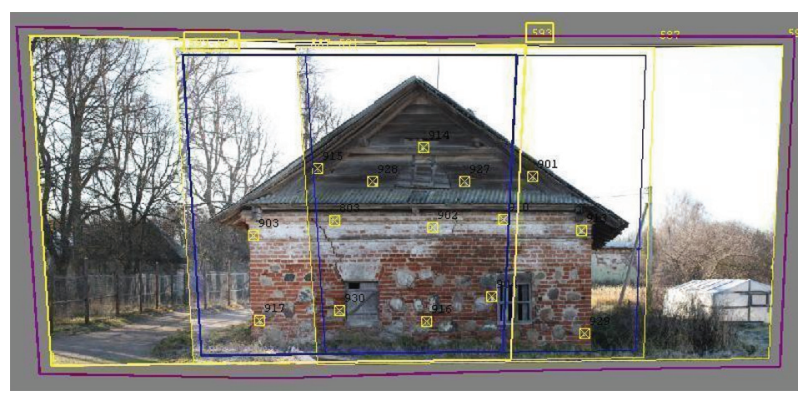

Fig. 1. Three overlapping images (593/587/591)

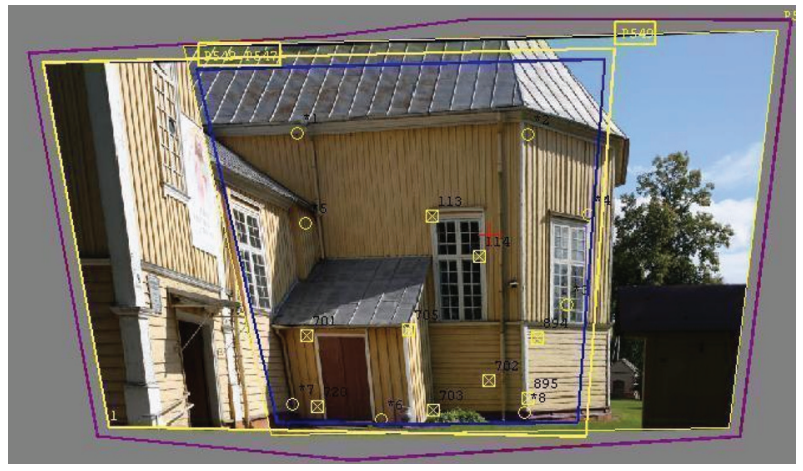

Fig. 2. Two overlapping images (547/549)

The facade of the first object (house) has a smooth surface (Fig. 1). The facade of the second object is advanced and has two different point measurement levels of the surface (Fig. 2). CP and Tie points are marked on the facade. All these points are used for the relative orientation of photogrammetric processes. CP have been 
measured considering the images of the manual (mono) and stereo modes of the first object. The correlation coefficients $(q)$ and vertical parallax residual $(E)$ of the measured points have been calculated following the measurement. Accuracy results are shown in Table 1.

Table 1. Accuracy analysis of point measurements using manual modes of the first object

\begin{tabular}{|c|c|c|c|c|}
\hline № of CP points & $q$ & $E, p x l$ & $q$ & $E, p x l$ \\
\hline \multicolumn{3}{|c|}{ Model of 593/587 } & \multicolumn{2}{|c|}{ Model of $587 / 591$} \\
\hline 803 & 0.996 & -0.011 & 0.997 & 0.002 \\
\hline 901 & - & - & 0.998 & 0.040 \\
\hline 902 & 0.994 & 0.014 & 0.997 & 0.006 \\
\hline 903 & 0.992 & -0.012 & - & - \\
\hline 904 & 0.996 & -0.133 & 0.996 & 0.148 \\
\hline 910 & 0.994 & 0.018 & 0.997 & -0.014 \\
\hline 913 & - & - & 0.998 & -0.067 \\
\hline 914 & 0.995 & 0.019 & 0.997 & -0.024 \\
\hline 915 & 0.995 & -0.001 & - & - \\
\hline 916 & 0.997 & 0.070 & 0.997 & 0.094 \\
\hline 917 & 0.995 & -0.130 & - & - \\
\hline 927 & 0.995 & -0.026 & 0.998 & 0.006 \\
\hline 928 & 0.994 & 0.006 & 0.996 & 0.009 \\
\hline 929 & - & - & 0.997 & -0.078 \\
\hline 930 & 0.995 & 0.184 & 0.997 & -0.119 \\
\hline \multicolumn{3}{|c|}{$E_{\text {mean }}=0.079 p x l$} & \multicolumn{2}{|c|}{$E_{\text {mean }}=0.070 p x l$} \\
\hline \multicolumn{3}{|l|}{$R M S=0.111 p x l$} & \multicolumn{2}{|c|}{$R M S=0.099 p x l$} \\
\hline
\end{tabular}

$$
\begin{aligned}
& \text { The result of image adjustment } \\
E_{x y(\text { mean })}= & 0.003 \mathrm{~m}, \quad E_{z(\text { mean })}=0.001 \mathrm{~m}
\end{aligned}
$$

Table 2. Accuracy analysis of point measurements using stereo modes of the first object

\begin{tabular}{c|c|c}
\hline \multirow{2}{*}{$\begin{array}{c}\text { No of CP } \\
\text { points }\end{array}$} & $\boldsymbol{E}, \boldsymbol{p} \boldsymbol{x l}$ & $\boldsymbol{E}, \boldsymbol{p} \boldsymbol{x l}$ \\
\cline { 2 - 3 } & Model of 593/587 & Model of 587/591 \\
\hline 803 & -0.084 & -0.513 \\
\hline 901 & - & 0.229 \\
\hline 902 & 0.140 & 0.017 \\
\hline 903 & - & -0.196 \\
\hline 904 & 0.161 & 0.084 \\
\hline 910 & -0.056 & 0.334 \\
\hline 913 & - & -0.744 \\
\hline 914 & 0.037 & 0.827 \\
\hline 915 & 0.133 & 0.154 \\
\hline 916 & -0.068 & - \\
\hline 917 & 0.012 & -0.106 \\
\hline 927 & 0.000 & -0.008 \\
\hline 928 & -0.193 & \\
\hline 929 & - & 0.060 \\
\hline 930 & -0.281 & $E_{\text {mean }}=0.369 p x l$ \\
\hline & RMS = $0.522 p x l$ \\
\hline
\end{tabular}

The result of image adjustment

$$
E_{x y(\text { mean })}=0.003 \mathrm{~m}, \quad E_{z(\text { mean })}=0.001 \mathrm{~m}
$$

The correlation coefficients $(q)$ of the measured points have not been calculated in stereo mode. The results of vertical parallax residuals are shown in Table 2.

The results of the first object show that the relative orientation and image adjustment of measuring manual and stereo points (Tables 1 and 2) are of similar and good quality. Consequently, if an object has a smooth surface, it is possible to measure the points manually or by stereo mode. The correlation coefficient $(q)$ is $0.992-1.00$.

As for the second object, two overlapping images (Model 549/547) have also been measured using CP manual and stereo modes. Accuracy results are shown in Tables 3 and 4 .

Table 3. Accuracy analysis of point measurements using manual modes of the second object

\begin{tabular}{c|c|c}
\hline \multirow{2}{*}{ No of CP points } & $\boldsymbol{q}$ & $\boldsymbol{E}, \boldsymbol{p x l}$ \\
\cline { 2 - 3 } & \multicolumn{2}{|c}{ Model of 549/547 } \\
\hline 701 & 0.991 & -1.962 \\
\hline 720 & 0.987 & -0.407 \\
\hline 703 & 0.994 & -1.238 \\
\hline 702 & 0.990 & 0.126 \\
\hline 114 & 0.989 & 2.254 \\
\hline 113 & 0.956 & 1.904 \\
\hline 895 & 0.963 & -0.066 \\
\hline 894 & 0.974 & 1.061 \\
\hline \multicolumn{3}{|c}{} \\
\hline & $E_{\text {mean }}=1.387$ pxl \\
\hline & $R M S=4.997$ pxl \\
\hline
\end{tabular}

The result of image adjustment

$$
E_{x y(\text { mean })}=0.035 \mathrm{~m}, E_{z(\text { mean })}=0.082 \mathrm{~m}
$$

\begin{tabular}{|c|c|}
\hline \multirow{2}{*}{ No of CP points } & $E, p x l$ \\
\hline & Model of 549/547 \\
\hline 701 & -0.304 \\
\hline 720 & 0.435 \\
\hline 703 & 0.308 \\
\hline 702 & -0.063 \\
\hline 114 & -0.408 \\
\hline 113 & 0.115 \\
\hline 895 & -0.160 \\
\hline 894 & 0.127 \\
\hline \multicolumn{2}{|c|}{$E_{\text {mean }}=0.148 p x l ; R M S=0.284 p x l$} \\
\hline
\end{tabular}

Table 4. Accuracy analysis of point measurements using stereo modes of the second object

The result of image adjustment

$$
E_{x y(\text { mean })}=0.003 \mathrm{~m}, E_{z(\text { mean })}=0.005 \mathrm{~m}
$$

The results of the second object indicate that the relative orientation and image adjustment of manual and stereo point measurements (Tables 3 and 4) are different. The results of the points measured in stereo mode are good enough; the mean errors of measurement points in the XY plane and $\mathrm{Z}$ coordinates are small. The results of point measurements and image adjustment applying 
manual mode disclose big blunders ranging from 0.03 to $0.08 \mathrm{~m}$. Consequently, if the points are measured on more than one surface, it must be done in stereo mode. The correlation coefficients of the image adjustment of manual mode are 0.960-0.991.

A comparison of the point vertical parallax $E_{\text {mean }}$ of measurement points on overlapping images and RMS image processing in manual and stereo modes are shown in Figs. 3 and 4.

A comparison of the results of image adjustment $\left(E_{x y(\text { mean })}, E_{z(\text { mean })}\right)$ in the images of manual and stereo modes are shown in Figs. 5 and 6.

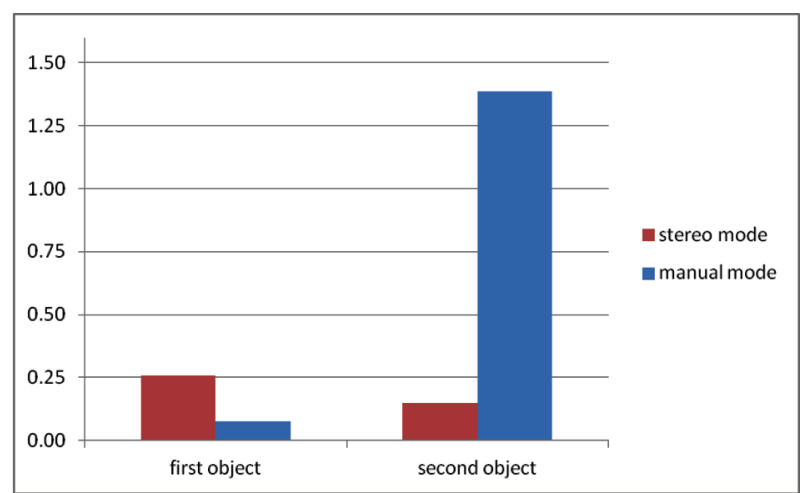

Fig. 3. Values of vertical parallax $E_{\text {mean }}$, in $p x l$

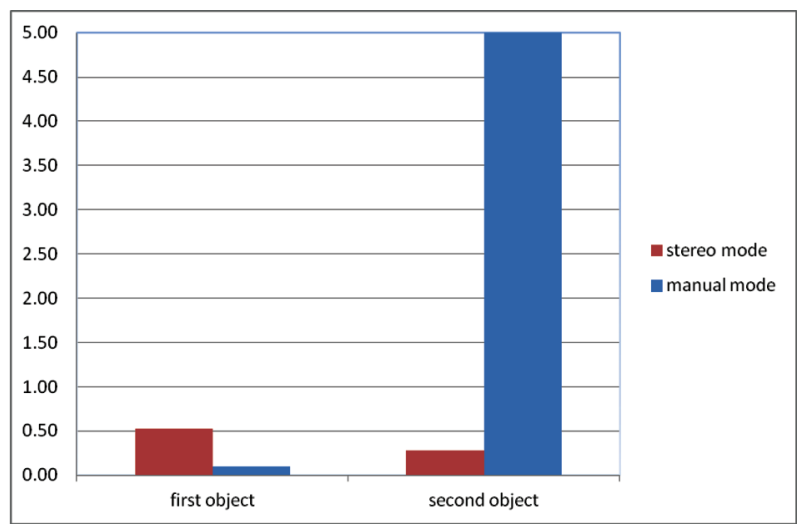

Fig. 4. Value of $R M S$, in $p x l$

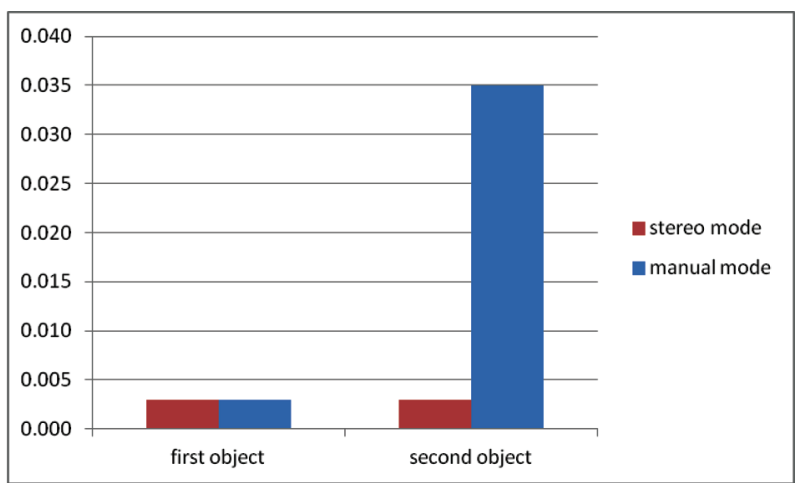

Fig. 5. Value of mean errors $E_{x y(\text { mean })}$, in m

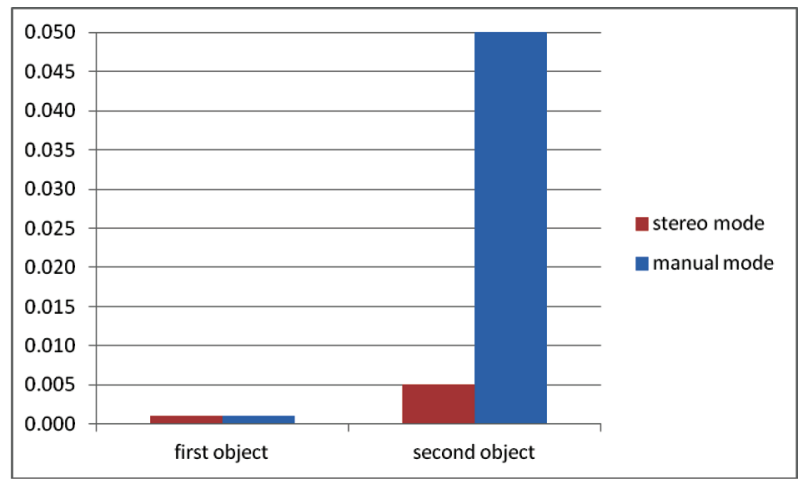

Fig. 6. Value of mean errors $E_{z(\text { mean })}$, in m

Figures 3-6 clearly indicate that the point measurements of the second object using manual (mono) mode has unacceptable errors, whereas the point measurements of the first object has been done using manual or stereo mode.

\section{Conclusions}

The images of two heritage objects have been taken for experimental investigation. Control points and tie points have been measured using stereo and manual mode. The control points of the first object are distributed on the surface of the smooth facade and on the surface of different (a few) levels.

The process of image matching of the smooth surface object points to the value of the determined correlation coefficient, which makes $0.992-1.00$. The mean error of the vertical parallaxes of the measured points makes $E_{\text {mean }}=0.07-0.15 \mathrm{pxl}$ and root mean squared $\mathrm{RMS}=0.01-0.21 p x l$. After image transformation (adjustment processes) to the $3 \mathrm{D}$ model, the accuracy of the measured points has reached $0.001-0.003 \mathrm{~m}$ and satisfies the requirement for creating an accurate digital terrain model and orthophoto generation.

Within the process of matching an image with an object having a different surface, the value of the correlation coefficient, which is $0.960-0.991$, has been determined. The mean error of the vertical parallax of the measured points is $E_{\text {mean }}=1.4 p x l$ and RMS $=5 p x l$ when points are measured manually. The result of image adjustment makes $0.04-0.08 \mathrm{~m}$. When the points are measured by stereo mode, vertical parallax $E_{\text {mean }}=0.15 \mathrm{pxl}$ and $\mathrm{RMS}=0.28 p x l$ and image adjustment result is 0.03-0.05 m. The results of stereo mode are more precise than those of manual mode.

Considering close-range photogrammetry during relative orientation, it is recommended that the value of the correlation coefficient should be not smaller 0.990 . The precise results of point measurements are obtained using stereo mode.

\section{References}

Hanke, K.; Grussenmeyer Corfu, P. 2002. Architectural Photogrammetry: Basic Theory, Procedures, Tools [online], [cited 20 January 2013]. Available from Internet: http://www.isprs. org/commission5/tutorial02/gruss/tut_gruss.pdf 
Kiseleva, A. S. 2002. Accuracy Control at Various Stages of Photogrammetric Processing in PhotoMod System. Moscow: Racurs.

Mileškaite, J. 2011. The application of the covariance method analysing the digital images of land surface, Geodesy and Cartography 37(3): 105-110. http://dx.doi.org/10.3846/139 21541.2011.626260

Potůčková, M. 2004. Image Matching and Its Applications in Photogrammetry: Ph.D. thesis [online], [cited 25 January 2013]. Available from Internet:

http://www.plan.aau.dk/digitalAssets/5/5516_314.pdf

Sužiedelytė-Visockienè, J.; Bručas, D. 2009a. Digital photogrammetry for building measurements and reverse-engineering, Geodezija ir kartografija [Geodesy and Cartography] 35(2): 61-65.

http://dx.doi.org/10.3846/1392-1541.2009.35.61-65
Sužiedelytė-Visockienè, J.; Bručas, D. 2009b. Influence of digital camera errors on the photogrammetric image processing, Geodezija ir kartografija [Geodesy and Cartography] 35(1): 29-33. http://dx.doi.org/10.3846/1392-1541.2009.35.29-33

Sužiedelytè-Visockienè, J. 2012. Photogrammetry requirements for digital camera calibration applying Tcc and MatLab software, Geodesy and Cartography 38(3): 106-110. http://dx.doi.org/10.3846/20296991.2012.728895

Jūratė SUŽIEDELYTE்-VISOCKIENĖ. Assoc. Prof., Dr at the Department of Geodesy and Cadastre, Vilnius Gediminas Technical University, Sauletekio al. 11, LT-10223 Vilnius, Lithuania. $\mathrm{Ph}+3705$ 2744703, fax +370 52744705 .

Doctor Vilnius Gediminas Technical University, 2003. Research interests: digital photogrammetry, land management. 